\title{
Servikal diskopatili bir olguda gelişen nöropatik ağrının akupunktur tedavisine dramatik yanit: Olgu sunumu
}

Dramatic response to acupuncture treatment of neuropathic pain in a case with cervical discopathy: Case report Ahmet Karakoyun ${ }^{1}$ iD , Gamze Yanartaş ${ }^{2}$

1 Fiziksel Tıp ve Rehabilitasyon ABD, Aksaray Üniversitesi Tıp Fakültesi, Aksaray/Türkiye

\section{ÖzeT}

Boyun ağrılarının en sık nedenlerinden biri olan servikal disk hernisi, sıklıkla boyun ağrısı ile birlikte kola yayılan ağrı, parestezi, duyu, motor ve refleks değişiklikleriyle seyreden radikülopatiye neden olur. Bu çalışmamızda 35 yaşında servikal diskopatisi olan, çeşitli tedavilere rağmen ağrısı geçmeyen ve cerrahi düşünülen erkek bir olguyu sunduk. Akupunktur uygulaması sonucunda hastamızın ağrılarının tama yakın düzeldiğini tespit ettik. Geçmişi oldukça eskilere uzanan akupunkturun günümüz modern tıbbında kullanımı ve saygınlığı giderek artmaktadır. Son 50 yılda dünyada pek çok ülkede, akupunktur teknikleri, alerjik hastalıklar, migren, diskojenik ağrılar ve diğer kas iskelet sistemi hastalıkları gibi çeşitli alanlarda yaygın olarak kullanılmaktadır. Akupunktur tedavisi bu yüzden boyun ve bel ağrısı gibi durumlarda ağrıyı önlemede etkili metotlardan birisidir ve gereksiz cerrahiyi azaltabilir.

Anahtar Kelimeler: : akupunktur, nöropatik ağrı, servikal diskopati

\section{ABSTRACT}

Cervical disc herniation, which is one of the most common causes of neck pain, often causes radiculopathy that spreads to the arm with neck pain and presents with pain, paresis, sensation, motor and reflex changes. In this study, we present a 35-year-old male patient with cervical discopathy who did not recover from pain despite various treatments. As a result of acupuncture application, we found that the pain of our patient was almost completely resolved. The use and respectability of acupuncture in modern medicine is gradually increasing. In the last 50 years, acupuncture techniques have been widely used in many countries around the world in various fields such as allergic diseases, migraine, discogenic pain and other musculoskeletal diseases. Acupuncture treatment is therefore one of the effective methods of preventing pain in conditions such as neck and low back pain and may reduce unnecessary surgery.

Keywords: acupuncture, neuropathicpain, cervicaldiscopathy

\section{GiRiş}

Boyun ağrısı, kas iskelet sistemi ağrıları içinde bel ağrılarından sonra en sık karşılaşılan problemlerden birisidir. Yaş, meslek, sedanter hayat tarzı, psikolojik bozukluklar, yatarak televizyon seyretme ve yastık şekli gibi alışkanlıklar boyun ağrısıyla ilişkili faktörlerdir (1).

Servikal diskopati, dejenere diskin servikal spinal sinir kökünü sıkıştırması sonucu ortaya çıkan bir durum olup daha çok 30-40 yaşlarında görülür (1). Çoklu anüler yırtıkların içine nükleus pulpozus girerek diskte çepeçevre bir taşma olur ki buna anüler bulging denir. Lokalize disk bulging durumuna protrüzyon, anulus fibrozusun tamamen yırtılıp kanalis vertebralis içine çıkmasına ekstrüzyon ve fıtıklaşan materyalin koparak epidural alanda serbest kalmasına sekestre disk veya serbest fragman denir $(2,3)$.

Servikal diskopati sıklıkla boyun ağrısı ile birlikte kola yayılan ağrı, parestezi, duyu, motor ve refleks değişiklikleriyle seyreden radikülopati durumuna neden olur. Manyetik rezonans görüntüleme, noninvaziv ve sensitif bir yöntem olarak servikal disk hernisini tanımlamak için sık olarak kullanılmaktadır $(2,3)$.

Servikal diskopati tedavisinde en sık yapılan tedavi şekli medikal tedavidir (NSAI, kas gevşeticiler vb.). Ancak bu ajanların uzun süre kullanılması gastrointestinal şikayetler, miyokard ve serebrovasküler iskemi riskini artırması nedeniyle fazla önerilmemektedir. Medikal tedaviler dışında egzersiz, fizik tedavi, alternatif tıp tedavileri ve cerrahi

Yazışma Adresi/Address for Correspondence: Ahmet Karakoyun, MD, Aksaray Üniversitesi Tıp Fakültesi, Fiziksel Tıp ve Rehabilitasyon ABD, 68100,

Aksaray/Türkiye

E-Posta/E-Mail: furkankk42@hotmail.com || Tel: +90 5306566550

Received/Geliş Tarihi: 25 Nov 2019 || Accepted/Kabul Tarihi: 11 Mar 2020

Bu Eser Creative Commons Atıf-Gayriticari 4.0 Uluslararası Lisansı Ile Lisanslanmıştır. This work is licensed under a Creative Commons

Attribution-NonCommercial 4.0 International License (CC BY-NC 4.0). 
yöntemler yapılan diğer tedaviler arasındadır. Disk cerrahisinin yüksek maliyeti ve riski, konservatif tedavi yöntemlerinin önemini günümüzde daha belirgin bir hale getirmiştir $(2,3,4)$. Bu sebeple son zamanlarda alternatif tedavilere ihtiyaç artmıştır. Akupunktur bu uygulamaların en sık bilinenlerindendir. Kronik kas-iskelet sistemi ağrılarında, impingement sendromu, akut lomber strain, kronik boyun ağrısı gibi birçok kas-iskelet sistemi problemlerinde etkili olduğu gösterilmiştir (5). Bu çalışmamızda uzun süreden beri servikal diskopatisi olan ve şikayetleri geçmediği için cerrahi tedavisi düşünülen ve akupunktur tedavisine dramatik bir şekilde yanıt veren bir erkek olgu sunduk.

\section{OLGU}

Otuz beş yaşında erkek hasta boyun, omuz ve kol ağrısı şikayetiyle polikliniğimize başvurdu. Anamnezinde daha önceleri çeşitli bölümlerde muayene olduğunu ve servikal diskopati tanısı konduğunu, çeşitli tedaviler gördüğünü belirtti. Hasta şikayetinin son üç ay içinde artarak devam ettiğini, kollarında ve ellerinde aralıklı olarak uyuşma ve his kaybının olduğunu ancak sabah tutukluğu ve güç kaybının olmadığını söyledi. Ağrı nedeni ile geceleri uyku düzeni ve kalitesinin bozulduğunu ifade ediyordu.

Fizik muayenesinde servikal eklemde sağa rotasyon, sola rotasyon ve fleksiyon hareket sonu ağrılı, servikal paravertebral adale spazmı bilateral mevcuttu. Kompresyon-distraksiyon testi (+), spurling testi (+)idi. Nörolojik muayenesinde C5-6 dermatomunda hipoestezi, derin tendon refleksleri doğal olarak gözlendi. Her iki üst ekstremitede motor güç kaybı ve patolojik refleks yoktu. Ağrısı VAS (0-10)'a göre 9, LANSS (Leeds Assessment of Neuropathic Symptoms and Signs Pain Scale)'a göre ise 14/24 olarak değerlendirildi.

\section{Tedavi Öncesi Servikal MRI bulgusu şu şekildeydi:}

C4-5 intervertebral diskinde posterior taşma mevcuttur. Duraya indentasyon vardır. Disk sinyal intensitesi azalmıştır. Sol nöral foramen daralmıştır. Kökler serbesttir.C5-6 intervertebral diskinde disko-osteofit kompleksine bağlı posterior taşma mevcuttur. Dura basılıdır. Disk sinyal intensitesi azalmıştır. Anüler fissürün eşlik ettiği küçük santral protrüzyon mevcuttur. Spinal kanal bu düzeyde daralmıştır. C6-7 santral protrüzyon mevcuttur. Her iki nöral foramenlerde kökler serbesttir. Spinal kanal bu düzeyde belirgin daralmıştır.

Olgumuza daha önceden çeşitli medikal tedaviler ve egzersiz programları uygulanmasına rağmen ağıı durumunda düzelme olmadığı için akupunktur tedavisi uygulandı.

Tedavide haftada bir seans olmak üzere kulak ve vücut akupunkturu uygulandı. Tedaviye üç ay süreyle her seansta 20 dakika olmak üzere haftada bir kez, daha sonra iki haftada bir kez olmak üzere altı ay devam edildi. Tedavi sırasında boyunda Tian Zhu (BL-10), He Gu (LI- 4), Nao Kong (GB -20), Shao Ze (SI -3) ;omuzda TianLiao (SJ-15), Bıng Feng (SI-12); sırtta Feng Men (BL-12), BL-13, JueYinShu (BL-14) ve kulakta: Anti depresyon noktası (non dominant kulak), ganglion servikale inferior ve ganglion stellatum, analjezi noktası (dominant taraf - altın iğne), valium-diazem noktası, Acth noktası, voltarennoktası (PGE1) noktalarına uygulama yapıldı. Kulakta Nogier yöntemi tercih edilmiştir.

Vücut için $0,25 \times 25$ mm-çelik ve $0,20 \times 13$ mm gümüş, servikal alanda $0,20 \times 13 \mathrm{~mm}$ çelik ve kulakta $0,16 \times 7 \mathrm{~mm}$ çelik ile 0,20x13 mm altın iğneler uygulandı. Kulak için özel kulak iğneleri uygulandı. Egzersiz ve günlük yaşam aktiviteleri anlatıldı. Altı ay sonra hastanın fizik muayenesinde servikal hareket açıklığı tam ve ağrısızdı. VAS ve LANSS skoru 0 düzeyine gerilemişti (Şekil-1). Nörolojik muayenesi doğaldı. Uyku düzeni normale döndü. Akupunktur tedavisi sırasında herhangi bir yan etkiye rastlanmadı.

Şekil 1. Akupunktur seansına göre VAS ve LANSS skorlarındaki değişim

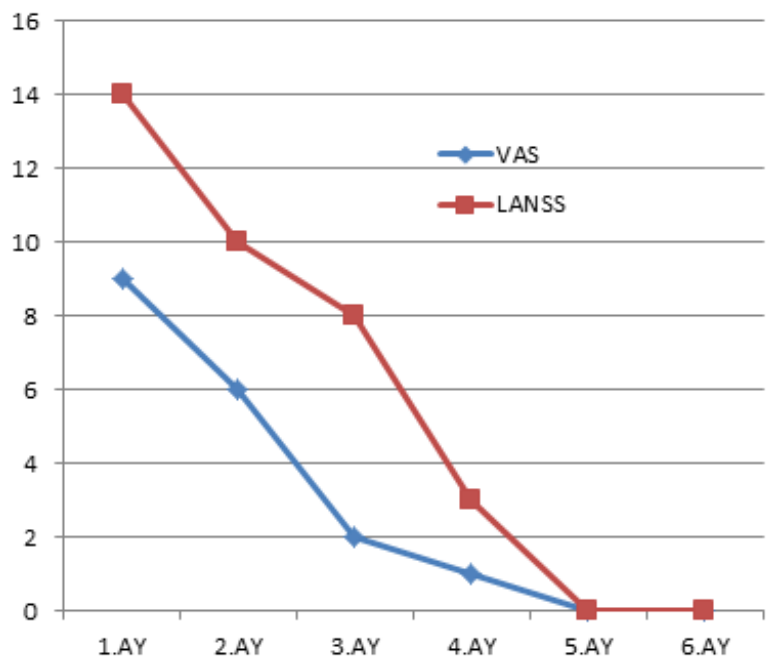




\section{Tedavi sonrası MRI bulguları şu şekildeydi:}

Vertebra korpus yükseklikleri, kortikomedüller sinyal intensiteleri tabiidir. C5-6 diskinde posterior santral bulging izlenmektedir.

C6-7 disk mesafesi daralmıştır. C6-7 diskinde diffüz bulging izlenmektedir. Tüm seviyelerde nöral foramenler ve foraminal sinirler tabiidir.

\section{TARTIŞMA}

Nöropatik ağrı periferal nosiseptörlerin uyarımı olmaksızın santral veya periferik sinir sisteminin yapısal lezyonları ve fonksiyon bozukluğuna bağlı olarak gelişmektedir. Nöropatik ağrı daha çok serebral veya spinal kord lezyonları sebebiyle oluşabilir (6).

Akupunkturun analjezik etkisi hayvan deneyleri ile gösterilmiştir. Kasları innerve eden sinirlerin uyarılması, spinal kord, orta beyin ve hipotalamo-hipofizer aksı uyararak endorfin ve enkefalin gibi nörotransmitterlerin salınımına neden olmaktadır (7). Dinorfin ve enkefalin salınımını artırarak spinal korda ağrı impuls girişini bloke eder. Orta beyinde monoamin-serotonin ve norepinefrin sinerjisi yoluyla spinal korda taşınan ağrı impulsunu inhibe eder. Pitüiter bezden beta endorfin salınımını artırıp serebrospinal sıvının kimyasına etki ederek hipotalamusta analjezi sağlar. Otonom sinir sistemi üzerindeki komplike etkileri de buna katkı sağlar (8). Bizim olgumuzda da akupunkturun etkisi benzer mekanizmalar ile endorfin salınımını arttırıp, proinflamatuvar sitokinleri azaltması ile açıklanabilir.

Acil cerrahi endikasyonlar dışında, disk hernilerinin tedavisinde konservatif metotların uygulanması olağandır. Alışılagelmiş klasik fizik tedavi modalitelerinin yanısıra, geleneksel Çin tıbbında önemli bir yeri olan akupunktur tedavisi, bu modalitelere ek olarak ya da bağımsız şekilde uygulanabilir (9).

Servikal diskopatide akupunktur uygulaması güvenilir ve etkin bir tedavi yöntemidir. Akupunktur uygulamasıyla ilgili çeşitli tedavi metotlarını karşılaştıran iyi planlanmış kontrollü çalışma sayısı çok azdır. Son yıllarda akupunkturun çeşitli hastalıklarda ağrı üzerine etkisi ile ilgili çeşitli çalışmalar yapılmıştır. Han ve ark. 2019 yılında yaptıkları bir çalışmada servikal diskopatili hastalarda akupunktur uygulanan hastalarda uygulanmayanlara göre ağrının azaldığını ve cerrahiye gitme oranının önemli derecede düştüğünü tespit etmişlerdir (10). İki bin on sekiz yılında yapılan başka bir çalışmada lomber diskopatili hastalarda akupunkturun servikal diskopatili hastalarda olduğu gibi ağrıyı önlediği ve cerrahiye gitme oranını azalttığı tespit edilmiştir (11). 2011 yılında Demirdağ ve ark. kronik lomber diskopatili hastaların tedavisinde akupunktur ve TENS tedavisini karşılaştırdıkları çalışmada ikisi arasında bir fark olmadığı, akupunktur uygulamasının ağrıyı azalttığı, dizabilite ve fonksiyonel durum üzerinde pozitif bir etki yaptığı tespit edilmiştir (12). Bizim çalışmamızda bulduğumuz sonuç daha önceki yapılan çalışmalarla uyumlu olup, tedavi sonrasında hastanın ağrı seviyesinde çok belirgin bir azalma saptanmış ve radyolojik olarak da regresyon görülmüştür.

Sonuç olarak; akupunktur, servikal diskopatili olgularda görülen ağrı üzerine etkili ve güvenli bir tamamlayıcı tıp metodudur. Aynı zamanda gereksiz cerrahi müdahaleyi de azaltmaktadır. Bu yüzden fizik tedavi modaliteleri ile kombine veya tek başına kullanılabilen akupunkturun bu alanda yararlı bir uygulama olduğu kanısına varılmıştır. Bununla ilgili çok kapsamlı ve daha fazla sayıda prospektif çalışmalara ihtiyaç duyulmaktadır.

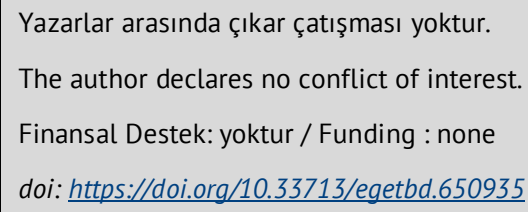

\section{KAYNAKLAR}

1. Carrol LJ, Hogg Johnson S,Van der Velde G, et al.Courseandprognostikfactorsforneckpain in the general populationResult of the Bon andjoıntdecade 2000-2010 Taskforce NeckPainandItsAssociatedDısorders.JmanipulativePhysiolTher 2009;3287-96

2. Şahin N, Karahan AY, Albayrak i. Effectiveness of physical therapy and exercise on pain and functional status in patients with chronic low back pain: a randomized-controlled trial. Turk J Phys Med Rehabil. 2018 Mar; 64(1): 52-58.

3. Şahin N, Albayrak I, Karahan AY, Uğurlu H. Kronik bel ağrılı hastalarda fizik tedavinin etkinliği. Genel Tıp Derg 2011;21 (1):17-20.

4. Kızıl R. Servikal disk hernileri. Türkiye Klinikleri Fiziksel Tıp ve Rehabilitasyon-Özel Konular 2009;2(3):35-43.

5. Vickers AJ, Cronin AM, Maschino AC, et al. Acupuncture for 
chronic pain: individual patient data meta-analysis. ArchInternMed 2012;172:1444-53.

6. Bebek N., Ertaş M. Nöropatik ağrı. Ağrı. 2007; 19(3): 5-10.

7. Pan $\mathrm{H}$, Xiao LW, Hu QF. Spontaneous regression of herniated cervical disc fragments and its clinical significance. Orthopaedic Surgery 2010;(2)1:77-79.

8. Gong CZ, Mega-Size Clinical Trials Prove Acupuncture's Effectiveness for Chronic Pain. nternational Journal of Clinical Acupuncture 2014;23(4):210 -215.

9. Saime A Y, Tur B S, Evcik D. Kas iskelet sistemi hastalıklarında sık uygulanan geleneksel ve tamamlayıcı tıp uygulamaları. Kocatepe Tıp Dergisi 2019;20(3):147-156.

10. Han DG, Koh W, Shin JS, et al. Cervical surgery rate in neck pain patients with and without acupuncture treatment: a retrospective cohort study. Acupunct Med 2019;37(5):268-276.

11. Koh W, Kang $K$, Lee $Y J$, et al. Impact of acupuncture treatment on the lumbar surgery rate for low back pain in Korea: a nationwide matched retrospective cohort study. PloS one, 2018;13(6). e0199042

12. Demirdağ, F., L. Ediz, A. Özgür, İ. Tekeoğlu. Kronik Lomber Disk HerniliHastalarin Tedavisinde Tens İle Elektroakupunktur Tedavisinin Karşılaştırılması. Van Tıp Dergisi 2011, 18(1):15-19. 